\title{
SOBRE PRÁTICAS INTEGRADORAS: UM ESTUDO DE AÇÕES PEDAGÓGICAS NA EDUCAÇÃO BÁSICA
}

\author{
A. L. S. HENRIQUE ${ }^{1}$ e J. M. NASCIMENTO ${ }^{2}$ \\ Instituto Federal de Educação, Ciência e Tecnologia do Rio Grande de Norte \\ ana.henrique@ifrn.edu.br*
}

Artigo submetido em julho/2015 e aceito em julho/2015

DOI: $10.15628 /$ holos.2015.3188

\section{RESUMO}

Trabalho de pesquisa de abordagem qualitativa e caráter exploratório que busca identificar a) os tipos de práticas integradoras utilizadas pelos professores no fazer pedagógico; b) as formas como essas práticas são sistematizadas; e, c) os vínculos dessas práticas com a Educação Básica. As análises são efetivadas tendo por base as comunicações orais apresentadas no Eixo 2 que trata das Práticas Integradoras em Educação Profissional do II Colóquio Nacional A Produção do Conhecimento em
Educação Profissional, realizado em 2013 no Instituto Federal de Educação, Ciência e Tecnologia do Rio Grande do Norte (IFRN). O estudo evidencia que as práticas integradoras comumente ocorrem articuladas a projetos de pesquisa e extensão esporádicos e desarticulados dos currículos de cursos de formação.Essas práticas integradoras são caracterizadas como:eventuais; intra, inter e pluridisciplinares; e de iniciativaindividual ou interinstitucional.

PALAVRAS-CHAVE: Práticas integradoras, interdisciplinaridade, educação básica.

\section{ABOUT PRACTICE INTEGRATORS: A STUDY EDUCATIONAL ACTIONS IN BASIC EDUCATION}

\begin{abstract}
Qualitative research work and exploratory which seeks to identify a) the types of integrative practices used by teachers in pedagogical practice; b) the ways in which these practices are systematized; and, c) the links of these practices with the Basic Education. The analyzes are accomplished based on oral communications presented on Axis 2 which deals with Integrative Practice in Education Professional II National Conference The Knowledge Production in Professional Education, held in
\end{abstract}

2013 at the Federal Institute of Education, Science and Technology of Rio Grande do North (IFRN). The study shows that the integrated practices commonly occur articulated sporadic research and extension projects and disjointed curriculum of courses formação.Essas integrated practices are characterized as possible; intra, inter and multidisciplinary; and iniciativaindividual interinstitutional.

KEYWORDS: Integrative practices, interdisciplinary, basic education. 


\section{INTRODUÇÃO}

O tema principal do presente texto são as práticas integradoras, motivo de preocupação dos professores diante da exigência de ações interdisciplinares, pluridisciplinares e transdisciplinares nos cursos de formação. Os docentes são cotidianamente desafiados às práticas pedagógicas que visem à integração ou ao diálogo entre diferentes disciplinas, cursos, áreas de conhecimento e instituições.

Nos últimos tempos, não tem sido fácil para muitos professores se envolverem ou promoverem esse tipo de integração por vários motivos: primeiro, os docentes não recebem formação específica para o desenvolvimento de práticas integradoras; segundo, as instituições de ensino/educação não organizam o currículo e a jornada de trabalho dos professores e alunos de forma a oportunizar a vivência de tais práticas; terceiro, não há disposição pessoal de professores em promoverem ações dessa natureza, pois alegam ser mais complexo o planejamento e a execução dessas ações.

Apesar dos dilemas e contradições, o fato é que, nos últimos anos, foram ampliadas as discussões sobre o tema e os marcos teóricos se alargaram. Expoentes como Nicolescu (1999), Edgar Morin (2000; 2001) ou Domingues (2004) teorizam sobre as diversas dimensões do diálogo disciplinar, dizendo que as relações entre saberes podem assumir os níveis da interdisciplinaridade, da pluridisciplinaridade ou da transdisciplinaridade consolidando sua epistemologia sobre a produção do conhecimento sistêmico ou em rede.

Não podemos negar o fortalecimento desse campo de conhecimento pelas pesquisas realizadas, sua sistematização e divulgação no meio acadêmico, no entanto, no âmbito das práticas docentes, notamos grande resistência da maioria dos professores por adotar iniciativas pedagógicas que promovam o diálogo interdisciplinar entre os saberes.

Há necessidade de estudos sobre a incidência de práticas integradoras dentro das instituições de ensino, especificamente, no interior dos institutos federais. No caso específico do Instituto Federal do Rio Grande do Norte, seu Projeto Político-Pedagógico e os projetos de cursos do Ensino Médio Integrado e das Licenciaturas que oferta, mantém a proposta do Projeto Integrador como possibilidade oficial de integração de saberes.

O Projeto Integrador se apresenta como oportunidade para o desenvolvimento de práticas integradoras entre disciplinas e cursos, fortalecendo a concepção de currículo integrado que visa à formação humana integral dos sujeitos.

A realização das reflexões em foco se justifica porque há carência da socialização das experiências pedagógicas capazes de promoverem a integração entre conceitos, disciplinas, cursos e áreas de conhecimento. Ainda temos professores que possuem a opinião de que é inviável ou até impossível a realização de práticas integradoras durante a vivência de currículos oficiais ou mesmo mobilizados por projetos de pesquisa e extensão.

Para analisar as ações pedagógicas de integração que ocorrem nas práticas docentes da Educação Básica nos institutos federais de educação ciência e tecnologia, se realizou estudo de 21 textos apresentados, na modalidade comunicação oral, no Eixo 2 do II Colóquio Nacional $A$ produção do Conhecimento em Educação Profissional, realizado em Natal, em 2013. Buscou-se nas 
ações pedagógicas, analisar a) que tipo de ação se constituiu; b) que áreas ou disciplinas foram envolvidas; c) de que forma se inseriram nas atividades da instituição; d) que metodologias foram utilizadas.

O corpus traça um mosaico do que vem ocorrendo nas Instituições de Ensino Superior, no sentido da materialização de práticas integradoras, pois representa uma amostra das ações pedagógicas em vários estados brasileiros como Rio Grande do Norte (IFRN), Paraíba (IFPB), Pernambuco (IFPE, IF Sertão PE), Maranhão (IFMA), Pará (IFPA), Santa Catarina, Brasília (IFB, UnB, UNEB), Rio de Janeiro (UFRRJ), São Paulo (UNICAMP), Minas Gerais (IFTM), Goiás (PUC-GO), Roraima (IFRR), Espírito Santo (IFES), Mato Grosso do Sul (IFMS). No total, temos cinco textos com identificação de universidades (UFRRJ, UNICAMP, UnB, UNEB, PUC-GO) e dezesseis provenientes dos IFs (Institutos Federais) das cinco regiões do país: norte (três), nordeste (seis), centro-oeste (dois), sudeste (quatro) e sul (um).

Para a consecução do objetivo proposto dividimos este texto em quatro itens, além da introdução: a primeira parte trata da epistemologia da interdisciplinaridade, da pluridisciplinaridade e da transdisciplinaridadecomo possibilidades de materialização de práticas integradoras; a segunda parte discute a relação entre a proposta de práticas integradoras e o currículo integrado; a terceira parte é dedicada às análises das ações pedagógicas de integração nos IFs com uma proposta de tipologia para essas práticas; e por último, são apresentadas as considerações finais sobre o estudo, em que destacamos que as práticas pedagógicas de integração ocorrem, na maioria das vezes, ligadas a projetos de pesquisa ou de extensão, e em atividades institucionais como feiras ou viagens de campo. Percebeu-se também que a participação docente é menor quando tais práticas estão propostas no próprio currículo do curso.

\section{INTERDISCIPLINARIDADE, PLURIDISCIPLINARIDADE, TRANSDISCIPLINARIDADE E PRÁTICAS INTEGRADORAS}

A disciplinaridade, a pluridisciplinaridade, a interdisciplinaridade e a transdisciplinaridade são as quatro flechas de um único e mesmo arco: o do Conhecimento. (NICOLESCU, 1999, p. 16 ).

A percepção da realidade de forma disciplinar, segundo Nicolescu (1999), é fruto da ciência moderna, que nasceu de uma ruptura brutal em relação à antiga visão de mundo e está fundamentada em três concepções basilares: a crença na existência de leis universais, de caráter matemático; a possibilidade de descoberta destas leis pela experiência cientifica; e a possibilidade de reprodutibilidade perfeita dos dados experimentais.

Ainda segundo esse autor, a complexidade, apoiada na explosão da pesquisa disciplinar,

[...] instala-se por toda parte, assustadora, terrificante, obscena, fascinante, invasora, como um desafio a nossa própria existência e ao sentido de nossa própria existência. A complexidade em todos os campos do conhecimento parece ter fago citado o sentido. (NICOLESCU, 1999, p. 16).

Por sua vez, contraditoriamente, a complexidade determina a aceleração da multiplicação das disciplinas. Entretanto, em que pese a grande contribuição do paradigma da simplicidade para a construção do conhecimento, essa perspectiva não abrange a diversidade de relações possíveis 
que existem na realidade, de forma que o conhecimento se torna compartimentalizado e isolado. Essa percepção foi consequência da própria explosão do conhecimento disciplinar. Em outras palavras, paradoxalmente, as concepções basilares que fundamentaram todo o edifício do conhecimento produzido levaram a conhecimentos que destruíram essas mesmas concepções.

Nicolescu (1999) recorda que as descobertas da Física, ainda que embasadas na causalidade local, na continuidade e no determinismo, mostraram como Plank, Bohr, Eisntein, fundadores da mecânica quântica, tiveram, como cientistas, "que se inclinar, não importando suas convicções religiosas ou filosóficas, diante das evidências experimentais e da autoconsistência teórica. (NICOLESCU, 1999, p. 06). A descontinuidade e o indeterminismo, que é constitutivo da realidade e não significa imprecisão ou acaso, instalam-se "no próprio coração da fortaleza da simplicidade: a física fundamental" (NICOLESCU, 1999, p. 16) e espraiam-se para outras ciências, modificando a percepção simplista da realidade. É a fagocitose do sentido, de que nos fala esse autor, o nascimento da percepção da existência de outras relações possíveis e da necessidade de estudálas a partir de outro paradigma. É o momento de religar os saberes construídos disciplinarmente.

A necessidade de religar os saberes traduziu-se pelo surgimento, na metade do século XX, da pluridisciplinaridade, da interdisciplinaridade e da transdisciplinaridade. De forma simplista, a pluridisciplinaridade diz respeito ao estudo de um objeto por várias disciplinas ao mesmo tempo. O ser humano, como objeto de estudo, por exemplo, pode ser analisado, entre outras ciências, sob a ótica da biologia, da antropologia ou da psicologia. Um conhecimento assim construído traz uma profícua contribuição ao objeto de estudo. Não se pode, esquecer, no entanto, como nos lembra Nicolescu (1999, p. 22), que essa contribuição circunscreve-se a uma mesma disciplina. Nas palavras do autor, "[...] a abordagem pluridisciplinar ultrapassa as disciplinas, mas sua finalidade continua inscrita na estrutura da pesquisa disciplinar".

Ainda para esse autor, a interdisciplinaridade, diz respeito à transferência de métodos de uma disciplina para outra e da mesma forma que a pluridisciplinaridade, ultrapassa as disciplinas, mas sua finalidade também permanece inscrita na pesquisa disciplinar.

Já a transdisciplinaridade,

[...] como o prefixo "trans" indica, diz respeito àquilo que está ao mesmo tempo entre as disciplinas, através das diferentes disciplinas e além de qualquer disciplina. Seu objetivo é a compreensão do mundo presente para o qual um dos imperativos é a unidade do conhecimento. (NICOLESCU, 1999, p. 22)

Retoma-se, nessa definição, o pilar da descontinuidade, ou seja, entre as disciplinas existem relações que (re)criam sentidos. Nesse sentido, Domingues (2004, p. 53), ao tratar da transdisciplinaridade, afirma que "a unificação se deverá dar com base em metodologias abrangentes e teorias unificadoras fortemente contextualizadas, capazes de se abrir a diferentes perspectivas, abrigar a diversidade das coisas e assim, instalar uma totalidade de conhecimentos 'ex-cêntrica', aberta e dinâmica". Essa mesma afirmação poderia ser utilizada para referir-se à inter ou à pluridisciplinaridade.

É importante frisar que os prefixos "trans", "inter" ou "pluri" não negam as disciplinas nem os especialistas, mas exigem a integração entre as disciplinas bem como a cooperação entre os especialistas e uma preocupação com o todo, para assim fazer frente à pulverização do conhecimento. 
Levando essa discussão para o âmbito escolar, não se pode esquecer que, na escola, qualquer decisão que se tome, consciente ou inconscientemente, tem por base a concepção de ser humano que se quer formar e o modelo de sociedade que se pretende. Em consequência, caso se pretenda formar um sujeito que compreenda a realidade e nela atue, é necessário que se eduque para a complexidade (ZABALLA, 2002). Educar para a complexidade implica ensinar para que o sujeito perceba as relações que constituem a realidade e a sociedade. Assim, o ensino baseado em um currículo inter, pluri ou transdisciplinar, apesar das diferenças dessas abordagens, se apresenta como a possibilidade de religar os conhecimentos e conhecer a realidade em suas relações constituintes.

Podemos nos perguntar, por que isso se faz necessário?

Estamos vivenciando uma época de crise e de novos problemas, temos a sensação da insuficiência dos velhos métodos científicos baseados na compartimentalização, na fragmentação, na redução ao simples e ao lógico-matemático. Não se trata aqui, como já afirmamos, de negar todo o avanço científico nem a produção de conhecimento ocorridos na história da humanidade. Trata-se de "trabalhar para que esse conhecimento seja mais lúcido, e se faça acompanhar do conhecimento do conhecimento" (HENRIQUE, 2005, p.14) que só pode ser adquirido religando, contextualizando os saberes hoje compartimentados, articulando as disciplinas umas às outras de maneira fecunda, como afirma Morin (2000; 2001).

Ainda, segundo Morin (2001), o pensamento complexo é transdisciplinar, articula o local e o global, enfrentando dois tipos fundamentais de pensamento fechado que ameaçam a humanidade: a posição nacionalista e religiosa, que se considera exclusiva e é a base para o fundamentalismo, para o racismo, para a xenofobia, por negar a alteridade e a diferença; e o pensamento tecnicista e tecnocrático, que admite apenas as dimensões quantitativa e econômica da realidade, desprezando a dimensão humana, e é um pensamento incapaz de compreender os problemas fundamentais do sujeito.

Esse pensamento reducionista deve dar lugar a "métodos que permitam estabelecer as relações mútuas e as influências recíprocas entre as partes e o todo" (MORIN, 2000, p. 14). Nessa discussão, poderíamos acrescentar uma pergunta feita por Nicolescu (1999): "Teria a complexidade sido criada por nossa cabeça ou se encontra na própria natureza das coisas e dos seres?"

Segundo o próprio autor, tanto ela foi criada por nossa cabeça como é constitutiva das coisas e dos seres. E explicita

A complexidade das ciências é antes de mais nada a complexidade das equações e dos modelos. Ela é, portanto, produto de nossa cabeça, que é complexa por sua própria natureza. Porém, esta complexidade é a imagem refletida da complexidade dos dados experimentais, que se acumulam sem parar. Ela também está, portanto na natureza das coisas. (NICOLESCU, 1999, p. 19)

Em trabalho anterior, Henrique e Oliveira (2005) afirmaram que, na teoria, já se percebeu a insuficiência do enfoque disciplinar para dar conta da complexidade do real. Na prática, já percebe-se também a insuficiência de nossa formação para planejar, (e acrescentamos) materializar atividades partindo de enfoques trans, inter ou pluridisciplinares. Em que pese essas constatações, entretanto, não se pode deixar de reconhecer a variedade de tentativas feitas pelos 
professores para, em seu espaço docente, desenvolverem práticas integradoras, numa perspectiva inter, trans ou pluridisciplinar.

A epígrafe presente no início deste item nos conduz à reflexão de que tanto a disciplinaridade, como a pluridisciplinaridade, a interdisciplinaridade ou a transdisciplinaridade são as quatro flechas de um único e mesmo arco: o do conhecimento. Aqui, enfatizamos que tanto a diferença entre cada uma dessas abordagens como a complementaridade entre elas contribuem para usarmos na materialização de práticas integradoras.

\section{PRÁTICAS INTEGRADORAS E CURRÍCULO INTEGRADO}

As práticas integradoras são assim denominadas porque mobilizam a integração entre sujeitos, saberes e instituições. Elas podem ocorrer em diversos níveis e envolvendo uma diversidade de elementos, de forma a propiciar a existência de uma rede de relações de saberes, o que se pode identificar como rede epistêmica.

A rede epistêmica é caracterizada pela efetiva relação entre noções, conceitos e paradigmas que se articulam entre si para a compreensão de uma dada realidade. 0 estabelecimento do pensamento sistêmico propicia maior acuidade e coerência durante o processo de apropriação de conhecimento, de maneira que o ato de conhecer sempre se fundamenta no movimento de interdependência entre a visão macro, cósmico-holística e a visão micro, nano-analítica.

Mas qual seria a finalidade de uma prática integradora? As práticas integradoras no campo da educação teriam o objetivo de atender ao princípio da dialogicidade entre os saberes. Sua existência nos contextos de formação escolar visa à promoção de uma percepção mais completa e complexa da realidade e dos problemas que assolam a humanidade.

Dentre as possibilidades de prática integradora, o projeto integrador se apresenta como componente curricular que oportuniza ações dessa natureza no interior dos projetos pedagógicos das instituições de ensino médio e superior de nosso país. A presença do projeto integrador no currículo oficial garante, de forma sistemática e contínua, o espaço para efetivação de ações pedagógicas que evidenciem a concepção de que o conhecimento é uma totalidade social historicamente construído.

Segundo Zen e Oliveira (2013), o Projeto Integrador é um componente curricular que difere dos demais porque não traz em sua essência nenhuma lista de conteúdos prescritos, mas se torna realidade a partir das necessidades de alunos e professores em estudar um determinado tema, que é gerador, para solucionar uma questão ou problemática do mundo do trabalho, do universo familiar, social, histórico e cultural.

Para Barreto et al $(2007$, p. 7) “[...] o Projeto Integrador não é mais uma disciplina da matriz curricular, mas uma metodologia voltada para a articulação entre os conhecimentos estudados nas disciplinas que integram cada período letivo, na perspectiva da interdisciplinaridade." Como metodologia de trabalho, revela a essência pedagógica de um curso e a natureza das práticas docentes instituídas. Diz respeito à ideologia que sustenta o currículo, baseado nos princípios da articulação e integração entre teorias-práticas e práticas-teóricas. O Projeto Integrador, nesse sentido, inspira atitude metodológica da problematização, pesquisação e socialização de novos conhecimentos. 
O Projeto Integrador é um tipo de prática integradora que visa superar tanto as dicotomias existentes entre teoria e empiria como a fragmentação historicamente construída entre as disciplinas e campos do conhecimento. Desde o Século XVI, se tem construído uma incoerente hierarquia entre as áreas da ciência, de forma que algumas delas foram classificadas como superiores e de maior prestígio que outras.

No Século XXI, conforme já afirmamos, se propõe a religação entre os diferentes saberes pela lógica do conhecimento sistêmico, em que não há saberes maiores ou menores, mas uma diversidade de saberes que se complementam. Isto ocorre porque os problemas da humanidade se tornaram tão complexos, que para sua compreensão, exigiu dos campos da ciência disposição para o diálogo, a interação e a integração.

A vivência do Projeto Integrador no currículo oficial de um curso técnico ou superior demonstra uma iniciativa concreta de materialização desse ideal, que se efetiva quando ocorre a problematização e reflexão de uma dada realidade, constituindo o diálogo inter/transdisciplinar e a unidade entre teoria e prática.

Para tanto, se fazem necessárias duas atitudes. Primeiro, a aceitação e o cultivo dessa concepção entre os professores. A compreensão de que o diálogo entre os diferentes campos de conhecimento exige uma nova ética baseada no respeito epistêmico, que significa a promoção de atitudes de alteridade e congruência com o que é diverso e contraditório. Segundo, a existência, nas instituições de ensino, das condições efetivas para que os envolvidos tenham tempo na carga horária de trabalho destinado à atividade e espaço físico disponível para as interações.

Essa lógica de integração que fundamenta o Projeto Integrador deve estar na essência de um modelo de currículo que tem como objetivo a formação humana integral e integrada, considerando os conhecimentos advindos da natureza, do trabalho, da tecnologia, da ciência e da cultura. Em suma, a prática integradora, a exemplo do projeto integrador, é fortalecida no contexto de um currículo integrado, aquele que prima por uma formação integral para o ser humano.

A essência da proposta de um currículo integrado considera as múltiplas dimensões do ser humano, contrariando qualquer visão unilateral que o restringe apenas à dimensão do cognitivo ou do manufatureiro.

Nessa discussão, algumas questões afloram: falar de currículo integrado é o mesmo de integração curricular? Há de se pesar os fundamentos filosóficos e epistemológicos que atribuem sentido ao termo integração e da maneira como esse currículo se organiza e se efetiva na prática. Pode-se pensar em integração quando a matriz curricular tem por estrutura disciplinas e nunca eixos temáticos, temas geradores ou núcleos de problematização?

A concepção de um currículo integrado rompe com a lógica da fragmentação e se estrutura nos princípios de uma formação de um sujeito completo e pluridimensional. Segundo Ramos (2008, p. 2), para tanto, se faz necessário uma outra concepção de fazer educação, de organizar a escola e o uso de outras práticas de ensino e aprendizagem:

Uma educação dessa natureza precisa ser politécnica; isto é, uma educação que, ao propiciar aos sujeitos o acesso aos conhecimentos e à cultura construídos pela humanidade, propicie a realização de escolhas e a construção de caminhos para a produção da vida. Esse caminho é o trabalho. O trabalho no seu sentido mais amplo, como realização e produção humana, mas também o trabalho como práxis 
econômica. Com isto apresentamos os dois pilares conceptuais de uma educação integrada: um tipo de escola que não seja dual, ao contrário, seja unitária, garantindo a todos o direito ao conhecimento; e uma educação politécnica, que possibilita o acesso à cultura, à ciência, ao trabalho, por meio de uma educação básica e profissional. É importante destacar que politecnia não significa o que se poderia sugerir a sua etimologia, a saber, o ensino de muitas técnicas. Politecnia significa uma educação que possibilita a compreensão dos princípios científicotecnológicos e históricos da produção moderna, de modo a orientar os estudantes à realização de múltiplas escolhas.

Quando Ramos (2008) realiza a proposição de um currículo integrado, ela o faz explicando os sentidos epistemológicos que fundamentam essa integração. Analisa o conceito de integração em três sentidos que se complementam, evidenciando: a concepção de formação humana; a relação entre Ensino Médio e Educação Profissional; e a relação entre parte e totalidade na proposta curricular.

O currículo integrado deve objetivar a formação omnilateral dos sujeitos, integrando trabalho, ciência, tecnologia e cultura. De forma que o primeiro sentido que atribui a essa integração é filosófico. "Ele expressa uma concepção de formação humana, com base na integração de todas as dimensões da vida no processo formativo." (RAMOS, 2008, p. 3).

O segundo sentido atribuído à integração está na defesa da indissociabilidade entre Educação Básica e Educação Profissional como ação essencial para a formação dos trabalhadores. De modo que seja ofertada "[...] uma formação profissional que possibilite aos sujeitos jovens e adultos se apropriarem de conhecimentos que estruturem sua inserção na vida produtiva dignamente." (RAMOS, 2008, p. 12).

A autora ainda explica que a integração deve expressar o terceiro sentido, que é o da interdependência entre os conhecimentos gerais e específicos. A ação busca desconstruir a hierarquia existente entre eles, descobrindo seus elos de ligação. Isto porque "não existe essa separação que o positivismo nos fez crer ao longo da história, com base na qual se naturaliza a ideia de que o professor da educação básica ministra as teorias gerais, enquanto o professor da formação técnica ministra as suas aplicações." (RAMOS, 2008, p. 16).

Desse modo, construir um currículo que tenha por fundamento a integração não significa realizar sobreposição de disciplinas afins. O esforço envolve a consolidação conceitual sobre a proposta e o desenvolvimento de estratégias de ação para viabilizar, na ação docente, a realização de práticas pedagógicas integradoras, aquelas que efetivamente integrem conhecimentos diversos para resolução de problemas.

\section{AÇÕES PEDAGÓGICAS DE INTEGRAÇÃO EM INSTITUIÇÕES PÚBLICAS DE ENSINO: UMA ANÁLISE DE PRÁTICAS DOCENTES}

Após análise dos 21 textos constituintes do Eixo 2 dos Anais do /l Colóquio Nacional A Produção do Conhecimento em Educação Profissional foram realizadas algumas reflexões em torno dos tipos das práticas integradoras vivenciadas nas instituições de Educação Básica e Ensino superior de nosso país, contemplando a proposição inicial, a saber: a) que tipo de ação se constituiu; b) que áreas ou disciplinas foram envolvidas; c) de que forma se inseriram nas atividades da instituição; d) que metodologias foram utilizadas. 
Percebeu-se que, na maioria dos textos ocorre uma dispersão de concepção sobre o conceito de prática integradora, de forma que a compreensão sobre o conceito está comumente atrelada apenas à noção de currículo integrado ou à educação integral ou à relação teoria e prática.

Quando os autores dos textos pesquisados fazem referência ao currículo integrado ou à educação integral, a citação aparece revestida de uma generalização conceitual, se restringindo apenas ao uso de termos exportados do projeto político pedagógico das instituições ou de um determinado curso. Ainda relacionam o conceito ao sentido "relação teoria e prática", quando realizam, no interior de uma mesma disciplina ou curso, o diálogo entre as dimensões teórica e empírica de uma temática em estudo.

Observamos equívocos conceituais sobre a compreensão de prática integradora presentes nas ações docentes analisadas nos arquivos do Eixo II. Os professores se referem à prática integradora quando:

a) relacionam um conteúdo a outros conteúdos no âmbito de uma mesma disciplina;

b) abordam o conteúdo, articulando teoria e prática;

c) realizam a interação entre a instituição de ensino e outras instituições ou a comunidade;

d) consideram espaços coletivos de discussão como oportunidade/possibilidade de integração.

A análise mostra que a maioria dessas práticas integradoras estão situadas em projetos de pesquisa e extensão, caracterizadas, pois, como iniciativas pontuais, atreladas à vigência de editais com cronogramas e prazos de conclusão das ações. Comumente, práticas integradoras dessa natureza não são incorporadas aos currículos dos cursos e nem sistematicamente são realizadas pelos sujeitos envolvidos.

Com base na análise dos textos apresentados no Colóquio, listamos a seguir uma tipologia para as práticas integradoras analisadas:

1. As práticas integradoras eventuais: de iniciativa individual do professor, ocorrem de forma interdisciplinar quando articulam saberes de disciplinas/áreas distintas e intradisciplinar quando realizam a articulação de conteúdos no interior de uma mesma disciplina. Essas práticas se materializam pela vivência de projetos de ensino e visitas técnicas.

A limitação das experiências individuais de professores reside na eventualidade da ação, que geralmente não está inserida na matriz curricular do curso, desprovida, pois, de uma regularidade que garanta uma integração contínua dos saberes. Ainda, a limitação das experiências que ocorrem na dimensão intradisciplinar está em abordar o conhecimento de forma fragmentada, ainda que promova a apropriação significativa do conteúdo pela relação entre a teoria e a prática.

2. Práticas integradoras em contexto de atividades institucionais: não possuem inserção nos currículos dos cursos e se materializam no interior de projetos de pesquisa, projetos de extensão, feiras e mostras científicas.

As iniciativas de práticas integradoras no contexto de projetos ocorrem tanto na dimensão institucional como interinstitucional, com intervenções na comunidade. As práticas integradoras institucionais podem articular ações de integração entre disciplinas, cursos e áreas de conhecimento, tais práticas se maximizam quando alcançam a dimensão interinstitucional. As 
iniciativas de práticas integradoras interinstitucionais possuem uma ampla capilaridade porque envolvem um maior número de participantes, uma diversidade de lócus de atuação e de áreas de conhecimento.

3. Práticas integradoras permanentes e curriculares: estão vinculadas à essência pedagógica de um curso ou uma instituição de ensino, se materializam em seminários temáticos, projetos integradores, temas geradores e transversais.

Esse tipo de prática integradora é efetivada no contexto de desenvolvimento de currículos de formação e respaldada por projetos pedagógicos institucionais.

Com base na tipologia apresentada, pudemos traçar um perfil das práticas integradoras presentes em cada texto analisado:

Texto 1: prática integradora eventual e intradisciplinar (Biologia Celular) nos Cursos Informática e Agricultura. Foco: integração entre conteúdos (visão integradora do conteúdo por meio de mapas conceituais), numa mesma disciplina, em cursos diferentes;

Texto 2: práticas integradoras em contexto de projeto de pesquisa, pluridisciplinar (envolve várias disciplinas das áreas de formação específica e geral) e Interinstitucional (Entre universidade e IFs). Foco: integração de disciplinas a partir de temas geradores;

Texto 3: prática integradora em contexto de projeto de pesquisa, interdisciplinar (Biologia, História e Geografia) e Institucional (Ensino Médio Integrado num IF). Foco: integração de disciplinas a partir de tema gerador;

Texto 4: prática integradora eventuale individual e intradisciplinar (Desenho Técnico e Arquitetônico) no Curso Técnico de Edificações. Foco: integração entre teoria e prática;

Texto 5: prática integradora em contexto de projeto de extensão, interinstitucional (IF e instituições públicas e privadas). Foco: integração entre teoria e prática, interação entre instituições e comunidade;

Texto 6: não trata de prática integradora, consiste em pesquisa bibliográfica e documental sobre o Proeja;

Texto 7: não trata de prática integradora, consiste em pesquisa bibliográfica e documental sobre educação integral;

Texto 8: prática integradora em contexto de pesquisa (pesquisação/aprendizagem colaborativa), pluridisciplinar (Tecnologia, Arte Digital, Educação) e interinstitucional (entre universidades públicas, privadas e IFs). Foco: integração entre disciplinas para a produção de novas tecnologias educacionais;

Texto 9: não trata de prática integradora, consiste em pesquisa de campo com entrevistas e análise documental sobre a implantação do Proeja, interinstitucional (Entre universidades públicas e IF);

Texto 10: não trata de prática integradora, consiste em pesquisa bibliográfica e documental sobre o processo de elaboração de um Projeto Pedagógico do Curso Técnico em Agropecuária;

Texto 11: não trata de prática integradora, consiste em pesquisa documental sobre o projeto integrador no Curso de Edificações; 
Texto 12: prática integradora eventuale intradisciplinar (Química) no Proeja. Foco: integração entre teoria e prática;

Texto 13: prática integradora eventuale intradisciplinar (Ensino da trigonometria pela utilização do Geogebra). Foco: integração de conteúdos numa mesma disciplina;

Texto 14: prática integradora em contexto de projeto de pesquisa, interdisciplinar (Tecnologias Digitais e Produção Artística) e interinstitucional (entre universidades). Foco: integração entre disciplinas para a produção de tecnologias educacionais no Proeja;

Texto 15: não trata de prática integradora, consiste em pesquisa bibliográfica que discute o conceito de formação humana;

Texto 16: não trata de prática integradora, consiste em pesquisa de campo sobre o conselho de classe como espaço formativo de integração docente;

Texto 17: prática integradora pontual, individual e intradisciplinar (Artes) no Curso Técnico em Agropecuária Integrado ao Ensino Médio. Foco: integração entre teoria e prática;

Texto 18: prática integradora em contexto de projeto de extensão (Proeja-Fic), interdisciplinar (Ciência, Português, História e Matemática) e interinstitucional (IF e Escolas Públicas Municipais). Foco: integração entre disciplinas para interação entre instituição e comunidade;

Texto 19: prática integradora eventuale intradisciplinar (Sistema de Telecomunicação). Foco: integração entre teoria e prática;

Texto 20: não trata de prática integradora, consiste em pesquisa bibliográfica sobre o ensino de história;

Texto 21: não trata de prática integradora, consiste em pesquisa bibliográfica sobre a organização pedagógica da Rede e-Tec.

Diante do traçado que perfila os registros das experiências apresentadas, podemos realizar algumas reflexões:

Dentre os 21 textos analisados, 9 (42,9\%) não tratam de prática integradora, são caracterizados como pesquisa bibliográfica, documental ou de campo, trabalhos que não relatam experiências de integração de nenhuma natureza. O conjunto desses textos realiza apenas reflexão teórica sobre temas diversos como Proeja - política educacional, Implantação Proeja, Educação Integral, Elaboração Projeto Pedagógico, Projeto Integrador, Formação Humana, Conselho de Classe, Ensino de História e Rede e-Tec. Os autores chegam a confundir o conceito de prática integradora com a própria sistematização do projeto integrador, documento orientador de ações integradoras; ou mesmo, cometem o equívoco de relacionar o conceito de prática integradora à função de um conselho escolar, espaço que oportuniza a integração entre pessoas. Desse modo, há uma compreensão equivocada sobre o conceito de integração, o que dificulta a efetivação desses tipos de práticas pedagógicas nos cursos e nas instituições.

Ainda podemos notar que, das práticas integradoras identificadas, $6(28,6 \%)$ são de caráter eventual. $O$ fato demonstra que a iniciativa pessoal funciona como motivação para realização da integração entre saberes intra ou interdisciplinares. São práticas integradoras efetivadas num contexto de eventualidade, distantes de um processo de sistematização curricular oficial de um 
curso ou instituição de ensino. Comumente, as experiências eventuais se apresentam como intradisciplinares, o que demonstra ainda a dificuldade por parte dos professores em estabelecer diálogo entre os diferentes campos de conhecimento.

Identificamos também $6(28,5 \%)$ relatos de práticas integradoras em contexto de atividades institucionais relacionadas a projetos de pesquisa (4) e extensão (2). Essas práticas estão vinculadas à vigência de editais que possuem prazo estipulado para conclusão dos cronogramas de atividades, o que nos leva a classificá-las também como esporádicas ou sazonais, apesar de possuírem grande poder de capilaridade e promoverem integração entre instituições. O fato que preocupa com relação a esse tipo de prática integradora é que essas ações não se consolidam como um elemento oficial dinamizador de cursos de formação. Ainda que envolvam alunos da Educação Básica e do Ensino Superior, esses projetos são desenvolvidos no interior de grupos de pesquisa ou em comunidades, desarticulados da prática docente em sala de aula. Os termos "integração" e "integrador" parecem estar citados nos textos dos projetos políticos pedagógicos para atender a clássica premissa "indissociabilidade entre ensino, pesquisa e extensão", mas não se materializam como componente curricular estruturante.

Identificamos também que nenhuma das práticas apresentadas nos artigos analisados alcançou o nível da transdisciplinaridade.O estudo denuncia a dificuldade de professores e alunos em superar a crença na especialização e fragmentação do conhecimento. A promoção de atitudes pedagógicas transdisciplinares se fundamenta no pensamento sistêmico, que ignora fronteiras e redomas epistemológicas para a compreensão da complexa realidade em que estamos inseridos.

Trabalhos anteriores mostram a existência de

A partir do envolvimento com esse conjunto de experiências, surgiram algumas inquietações sobre a efetivação de práticas integradoras na Educação Básica e no Ensino Superior:

- Por que projetos eventuais possibilitam a adesão de um maior número de professores e alunos na consecução dessas práticas?

- Por que as propostas de práticas integradoras atreladas ao currículo de cursos sofrem resistência em sua efetivação?

- Quais elementos mobilizam os sujeitos a se envolverem em práticas integradoras eventuais e a resistirem às que são propostas em currículo de cursos?

Trata-se de uma problemática capaz de mobilizar várias pesquisas em torno do tema. Por não se tratar do foco de nossa análise, não vamos responder, neste trabalho, a tais questionamentos. Entretanto, eles surgem a partir da materialização de práticas integradoras reais,efetivadas por docentes em instituições de ensino, o que, indica que o conceito de currículo integrado ainda está em processo de construção. A integração não se manifesta articulada à dimensão curricular em plenitude, mas não podemos deixar de admitir que as práticas integradoras ocorrem, ainda que subvertam o seu real sentido. De certo modo, podemos afirmar que algo se move evai de encontro à argumentação expressa de que é impossível trabalhar pedagogicamente na perspectiva da integração.

Essa afirmação encontra eco em outros trabalhos (IFRN, 2011; e Henrique et al, 2011) que analisam práticas integradoras no IFRN.

A pesquisa relatada em IFRN (2011) 
[...] permitiu concluir que, em todos os campi investigados, há práticas que contribuem para a integração curricular. Não obstante, em geral, tais atividades não ocorrem de forma sistematizada e mediante uma ação coordenada, mas por iniciativas individuais ou de grupos. (IFRN, 2011).

Além disso, também são práticas que ocorrem ligadas a projetos de pesquisa, a aulas de campo e a eventos técnico-científicos, como feiras, seminários e exposições.

A essa constatação também chegaram Henrique et al (2011), que, aprofundando um pouco a discussão, mostraram que algumas práticas integradoras no IFRN ocorrem ligadas à participação em atividades que envolvem várias disciplinas; à participação em projetos de pesquisa ou de extensão; e à realização de visitas técnicas e aulas de campo.

Em ambos os trabalhos acima referenciados não se encontrou menção a práticas integradoras decorrentes da materialização do Projeto Integrador, não obstante, esse componente curricular esteja previsto nos projetos de curso e no Projeto Político-pedagógico do IFRN.

De uma maneira geral, pois, percebe-se um movimento em relação à existência de práticas pedagógicas de integração, embora não sistematizadas e/ou inclusas nos currículos e projetos de cursos.

\section{CONSIDERAÇÕES FINAIS}

Em suma, o presente trabalho possibilita-nos ampliar reflexões a respeito das práticas integradoras e sobre as modalidades de materialização dessas no âmbito das ações pedagógicas. Reconhecemos aqui o esforço dos sujeitos envolvidos na materialização de práticas integradoras. As referidas iniciativas representam avanço com respeito às tentativas de experimentar a vivência de novos paradigmas de pensamento e ação.

Todavia, tratar de práticas responsáveis pela integração entre conceitos, disciplinas e áreas de conhecimento, ainda significa relacioná-la as questão epistemológica envolta por imprecisões e equívocos. Os sujeitos envolvidos nas ações implementam práticas que integram, mas estão distantes da dimensão sistêmica dos currículos oficiais de formação.

Os trabalhos analisados encaminham ações que viabilizam o diálogo entre saberes no interior de uma mesma disciplina ou entre disciplinas de áreas de conhecimento. No entanto, ainda se ausentam da perspectiva transdisciplinar anunciada por Morin (2000; 2001) e Nicolescu (1999). O pensamento complexo e o currículo sistêmico apresentam-se como desafios a serem enfrentados pelos que pensam e fazem as instituições de ensino de nosso país.

As questões relacionadas à integração curricular e ao currículo integrado demandam maior estudo porque ultrapassa as noções de união, justaposição, relação e articulação entre saberes. A ideia-ação da integração não admite a fragmentação e o distanciamento entre áreas de conhecimento, ainda que, aparentemente, sejam paradoxais. Essa compreensão inaugura um novo tempo, o da ação pedagógica que cultiva o pensamento sistêmico.

\section{REFERÊNCIAS BIBLIOGRÁFICAS}

1. BARRETO, Ana Beatriz Pérez Cabrera Mafra et al. Uma experiência interdisciplinar: o Projeto 
Integrador na Licenciatura em Espanhol do CEFET/RN. In: Holos, ano 23, v. 3, p. 1-12, 2007.

2. DOMINGUES, Ivan (Org.). Conhecimento e transdisciplinaridade. Belo Horizonte: Editora UFMG, 2004.

3. HENRIQUE, Ana Lúcia Sarmento; OLIVEIRA, Leonor Araújo Bezerra. Enfoque globalizador, transdisciplinaridade e complexidade; uma nova perspectiva para o ensino a distância no CEFET-RN. In: HENRIQUE, Ana Lúcia Sarmento; SOUZA, Samir Cristino de (Org.). Transdisciplinaridade e complexidade: uma nova visão para a educação no século XXI. Natal: Editora CEFET-RN, 2005.

4. HENRIQUE et al. Práticas pedagógicas de integração no PROEJA-IFRN: o que pensam professores e estudantes. In: Inter. Ação. v. 36, n. 2, 2011, p.451-468.

5. INSTITUTO FEDERAL DE EDUCAÇÃO CIÊNCIA E TECNOLOGIA DO RIO GRANDE DO NORTE - IFRN. Relatório da pesquisa investigando a implementação do ensino médio integrado aos cursos técnicos de nível médio no CEFET-RN a partir de 2005: o currículo e a gestão. Natal, 2011.

6. MORIN, Edgar. Os sete saberes necessários à educação futuro. São Paulo: Cortez, 2000.

7. MORIN, Edgar. La mente bien ordenada: repensarla reforma, reformar elpensamiento. Barcelona: Seix Barral, 2001.

8. NICOLESCU, Basarab. O Manifesto da Transdisciplinaridade. São Paulo: Triom, 1999.

9. RAMOS, Marise. Concepção do Ensino Médio Integrado. 2008. Disponível em: <http://www.nre.seed.pr.gov.br/wenceslaubraz/arquivos/File/curriculo_integrado.pdf>. Acesso em: 12 jan. 2015.

10. ZABALLA. Antoni. Enfoque globalizador e pensamento complexo: uma proposta para o currículo escolar. São Paulo: Artmed, 2002.

11. ZEN, Eliezér Toretta; OLIVEIRA, Edna Castro de. O projeto integrador e a centralidade do trabalho para a formação humana no programa de integração da educação profissional com a educação básica na modalidade de educação de jovens e adultos (proeja) IFES Campus Vitória/ES. In: Colóquio Nacional - A Produção do Conhecimento em Educação Profissional, 2. Natal: IFRN, 2013. Anais... Disponível em: <http://portal.ead.ifrn.edu.br/coloquiopublicacoes-2/2013-2/anais>. Acesso em: 02 jan. 2015. 